\title{
Perancangan Sistem Pendataan Permohonan Surat Izin Mendirikan Bangunan di Kecamatan Lubuk Sikarah Kota Solok
}

\author{
Refli Noviardi ${ }^{1}$, Harfebi Fryonanda ${ }^{2}$ \\ ${ }^{1)}$ Sistem Informasi, Institut Teknologi Batam Sekupang Kota Batam \\ ${ }^{2)}$ Sistem Informasi, Institut Teknologi dan Bisnis Kalbis \\ Jalan Pulomas Selatan Kav 22 Jakarta 13210 \\ ${ }^{1)}$ Email: reflinoviardi@gmail.com \\ ${ }^{2)}$ Email: harfebi.friyonanda@kalbis.ac.id
}

\begin{abstract}
This research has been done on Lubuk Sikarah subdistrict office city of Solok by collecting data because the system that used to work still not optimal. Therefore, analysis of the data collected by the system design tool that aims to optimized IMB data processing using Java Netbean programming language and database MYSQL. This research method used is a field of research, there are research libraries and research laboratories. Thus, it produced a new system analysis using tools such as ASI(Flow Information System), DFD(Data Flow Diagram), ERD(Entity Relationship Diagram), and the Context Diagram. These tools will be generated several interrelated files in a database management. And the new system is expected to improve the quality of IMB petition data processing sistem on suddistrict of Lubuk Sikarah Office.
\end{abstract}

Keywords: data collecting system, imb, java, mysql

\begin{abstract}
Abstrak: Penelitian ini dilakukan pada Kecamatan Lubuk Sikarah Kota Solok dengan cara mengumpulkan data-data karena sistem yang digunakan untuk kerjanya masih belum optimal. Oleh Karna itu dibutuhkan analisis terhadap sistem yang sedang berjalan sehingga pendataan permohonan dapat menjadi lebih baik, efektif dan efisien dengan menggunakan bahasa pemograman java neatbean 7.0 dan database MYSQL Adapun metode penelitian yang digunakan adalah penelitian lapangan, penelitian perpustakaan dan penelitian laboratorium. Sehingga dihasilkan sebuah analisa sistem baru dengan menggunakan alat bantu seperti ASI (Aliran Sistem Informasi), DFD (Data Flow Diagram), ERD (Entity Relationship Diagram), dan Context Diagram. Dengan alat bantu inilah nantinya akan dihasilkan beberapa file yang saling berkaitan dalam sebuah manajemen database. Dan sistem yang baru ini diharapkan dapat meningkatkan kualitas informasi dan kerja dari sistem pendataan permohonan IMB.
\end{abstract}

Kata kunci : IMB, Java, mysql, sistem pendataan

\section{PENDAHULUAN}

Peraturan Pemerintah No. 36 tahun 2006 tentang peraturan pelaksanaan undang-undang No. 28 tahun 2002 tentang bangunan gedung. Bagunan yang dimaksud adalah wujud fisik hasil pekerjaan konstruksi yang berfungsi untuk tempat penyimpanan, perlindungan, pelaksanaan kegiatan yang berada diatas atau dalam tanah atau air.[1] Surat Izin Mendirikan Bangunan merupakan syarat awal dalam pendirian sebuah bangunan di Indonesia. Tanpa adanya surat ini bangunan yang berdiri akan dikategorikan sebagai bangunan ilegal[2] dan akan dilakukan pembongkaran oleh dinas yang terkait di kota setempat begitu juga dengan bangunan yang tidak sesuai dengan ketetapan yang telah dibuat di dalam surat izin mendirikan bangunan, maka bangunan tersebut akan dibongkar atau dirobohkan.

Kota Solok merupakan sebuah wilayah daerah tingkat dua yang ada di wilayah propinsi sumatera barat yang berbentuk kota. Yang mana menurut Peraturan daerah kota solok nomor 13 tahun 2012 wilayah kota solok seluas kurang lebih $5.7640 \mathrm{Ha}$ yang terdiri dari 2 (dua) kecamatan yaitu Kecamatan Lubuk Sikarah dan KecamatanTanjung Harapan [3]. Dengan batas-batas wilayah sebagai berikut: 
a) Sebelah Barat berbatasan dengan Nagari Selayo Kabupaten Solok, Limau Manis (Padang Luar-Kota) Kota Padang dan Koto Sani Kabupaten Solok; b) Sebelah Timur berbatasan dengan Nagari Guguak Sarai, Sawok Lawas dan GauangKabupaten Solok; c) Sebelah Selatan berbatasan dengan Nagari Selayo, Koto Baru dan Panyangkalan Kabupaten Solok; dan d) Sebelah Utara berbatasan dengan Nagari Tanjung Bingkuang, Aripan dan Kuncir Kabupaten Solok.

Dengan luas daerah seperti yang telah dijelaskan sebelumnya dibagi menjadi instansi dinas yang akan melayani masyarakat kota solok dalam segala bentuk pelayanan publik. Hal ini diperkuat dengan perda kota solok nomor 5 tahun 2016 tentang pembentukan dan susunan perangkat daerah. salah satunya adalah dinas pekerjaan umum dan tata ruang yang mengurusi mengenai izin mendirikan bangunan (IMB) di kota solok [4]. Dalam pengurusan IMB kota solok yang dilaksanakan oleh dinas terkait yang didukung oleh kecamatan yang melakukan tugasnya dalam membantu pengawasan IMB yang telah diterbitkan yang oleh dinas terkait yang tercantum dalam perda kota solok mengenai SOP kecamatan Lubuk Sikarah Kota Solok yang tercantum pada peraturan walikota solok nomor 59 tahun 2017 tentang tentang Standar operasional prosedur Kecamatan lubuk sikarah [5]. Dan untuk mendukung kinerja kecamatan dalam melaksanakan tugasnya dalam hal ini adalah kepengurusan IMB maka perlu dibuat sistem yang dapat mengolah data yang dibutuhkan oleh kecamatan dan mempermudah kepengurusan surat pengantar IMB oleh pemohon untuk diteruskan kepada dinas pekerjaan umum dan tata ruang.

Aplikasi pendataan data IMB merupakan sebuah sistem yang membantu dalam pengolahan data agar data yang diolah rapi aman dan akurat.

\section{METODE PENELITIAN}

\section{A. Kerangka Kerja}

Kerangka kerja diperlukan dalam mengerjakan sebuah penelitian dengan membuat sebuah tahapan metodologi penelitian untuk penelitian yang dikerjakan tidak terjadi kerancuan selama pengerjaan penelitian ini dan hasil yang dicapai menjadi lebih maksimal . kerangka kerja pada penelitian ini dapat dilihat pada Gambar 1.

\section{B. Tahapan- tahapan kerangka kerja}

\section{Melakukan Studi Literatur}

Studi Kepustakaan yang akan digunakan oleh penulis adalah literatur, literatur yang dimaksud

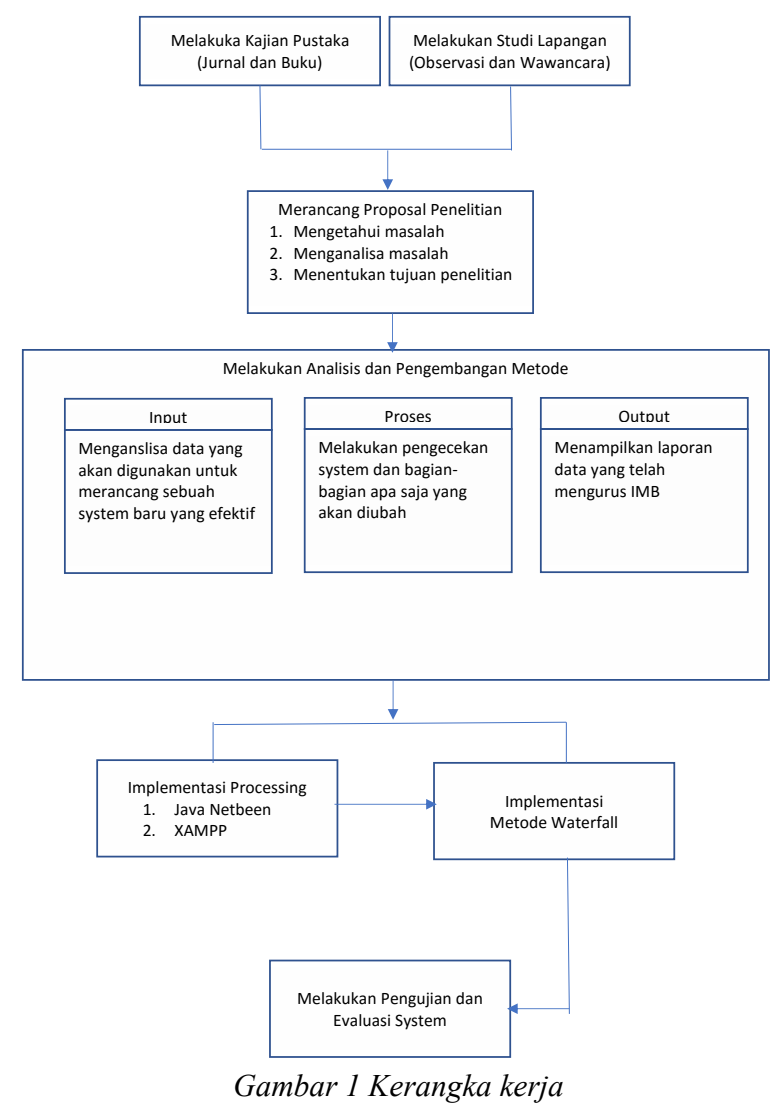

adalah literatur yang digunakan untuk mendapatkan suatu cara atau prosedur yang digunakan dalam merancang sistem informasi.

Sumber literatur didapatkan dari jurnal, dan buku-buku yang membahas tetntang cara merancang sebuah system yang efektif dan efisien dibandingkan dengan system yang lama atau yang sedang berjalan dalam hal ini adalah kepengurusan IMB.

\section{Melakukan Studi Lapangan}

Untuk mendapatkan data yang akan digunakan dalam penelitian dalam pembuatan system pendataan kepengurusan surat izin mendirikan bangunan ini, peneliti melakukan studi lapangan dengan melakukan observasi berupa wawancara dan melihat secara langsung terhadap staff dan kepala bagian terkait dengan pengurusan IMB di Kecamatan Lubuk Sikarah Kota Solok.

\section{Menyusun Rencana Penelitian}

Setelah mendapatkan gambaran melalui studi literature mengenai system informasi pendataan pembuatan surat izin mendirikan bangunan yang akan dirancang dan data-data mengenai pembuatan IMB sehingga peneliti dapat menetapkan beberapa hal yaitu: a) Mengetahui masalah. Langkah awal dalam penyusunan proposal adalah menjabarkan masalah dalam penelitian yang akan dilakukan, dalam hal ini adalah bagaimana membuat suatu 
rancangan sistem pendataan pembuatan IMB; b) Menganalisa masalah. Setelah menemukan definisi masalah yang akan dikerjakan, langkah selanjutnya menganalisa masalah yang ada saat pembuatan surat izin mendirikan bangunan ini; c) Menentukan tujuan masalah. Tujuan dari penelitian ini adalah bagaimana Sistem membantu dalam pendataan masyarakat yang ingin mengurus IMB sehingga proses data berjalan efektif dan efisien

\section{Melakukan analisa proses dan pengembangan metode}

Setelah mengetahui, definisi, masalah dan tujuan dari penelitian langkah selanjutnya melakukan analisa proses dan pengembangan dengan menjabarkan dalam tiga fase yaitu input, proses output: a) Input. Data yang dinputkan merupakan hasil wawancara dan observasi secara langsung mengenai proses pembuatan IMB yaitu data pemohon, Bangunan; b) Proses. Langkah selanjutnya adalah menganalisa data yang telah dinputkan dan menetukan variabel dan hasil melalui sebuah form yang akan menggabugkan data pemohon dan bangunan menjadi data permohonan IMB; c) Output. Hasil keluaran dari proses ini menghasilkan laporan data pembuatan Izin mendirikan bangunan.

\section{Implementasi sistem}

Agar system yang dirancang ini bisa dipakai oleh para staff terkait, maka rancangan system ini dibuatkan aplikasinya menggunakan Bahasa pemrograman java netbean dan SQL

\section{Melakukan pengujian sistem dan aplikasi.}

Apabila sistem aplikasi telah selesai rancang, langkah selanjutnya adalah melakukan pengujian terhadap aplikasi yang dirancang dan dilakukan perbaikan dan evaluasi apakah Sistem yang dirancang telah sesuai dengan tujuan yang telah ditetapkan.

\section{HASIL DAN PEMBAHASAN}

\section{A. Analisa Sistem.}

Sebelum melakukan perancangan terhadap suatu sistem, terlebih dahulu harus diteliti secara jelas sistem yang sedang berjalan pada Kantor Kecamatan Lubuk Sikarah Kota Solok. Hal ini bertujuan agar dapat diketahui lebih jelas permasalahan-permasalahan dan kendala-kendala yang dihadapi. Setelah melakukan beberapa penelitian dan penganalisaan pada Kantor Kecamatan Lubuk Sikarah Kota Solok didapat gambaran ringkas tentang keadaan sistem yang sedang berjalan pada kantor tersebut dan ditemukan beberapa kelemahan.
Belum dioptimalkannya penerapan sistem teknologi informasi terutama dari segi pengolahan data yang masih manual dan Penyimpanan data yang masih berupa buku catatan, sehingga resiko akan kehilangan data akan sangat besar. Tahap analisa sistem dilakukan sebelum tahap desain sistem (desain sistem). Tahap analisa merupakan tahap yang kritis dan penting, karena kesalahan ditahap ini dapat menyebabkan kesalahan pada tahap selanjutnya.

Pada tahap analisa sistem ini terdapat beberapa langkah-langkahdasaryangharusdilakukanolehanalis sistem, antara lain: Identify, yaitu mengidentifikasi masalah; Understand, yaitumemahami kerja dari sistem yang ada; Analyze, yaitu menganalisa system; dan Report, yaitu membuat laporan dari analisa.

\section{B. Analisa Sistem Berjalan}

Analisa system berjalan bertujuan untuk mengetahui bagaimana terjadinya proses pengolahan data permohonan surat mendirikan bangunan pada kantor Kecamatan Lubuk Sikarah Kota Solok dan juga mengetahui masalah-masalah dan kelemahan pada sistem yang sedang berjalan saat ini jika sistem lama terdapat kekurangan maka dapat disempurnakan dengan menggunakan sistem baru.

Aliran Sistem berjalan merupakan gambaran perpindahan data dari satu entity ke entity lainnya, adapun aliran sistem informasi lama yang sedang berjalan saat ini kantor Kecamatan Lubuk Sikarah Kota Solok:

Pelapor diwajibkan untuk membawa persyaratan pembuatan surat izin mendirikan bangunan yang telah di tetapkan antara lain: 7 (tujuh) Lembar fotokopi KTP; 7 (tujuh) Lembar fotokopi lunas PBB; 7 (tujuh) Lembar fotokopi surat rekomendasi dari kelurahan; 7 (tujuh) Lembar fotokopi surat pernyataan sepadan dari tetangga sebelah menyebelah; 7 (tujuh) Lembar fotokopi surat keterangan tanah; 7 (tujuh) Lembar fotokopi pernyataan perlepasan hak tanah; 7 (tujuh) Lembar fotokopi gambar rencana bangunan; 7 (tujuh) Lembar fotokopi denah lokasi; dan 7 (tujuh) Lembar fotokopi map snelhecter. Untuk lebih jelasnya gambaran aliran sistem informasi yang sedang berjalan, dapat dilihat dari Gambar 2.

\section{Aliran Sistem Usulan}

Bagian ini merupakan kerangka dasar yang ditunjukkan sebagai bahan usulan untuk mengembangkan sistem yang baru. Sistem baru ini akan memperbaiki kerja sistem pengolahan data tanpa menggangu stabilitas sistem. Pada bagian ini entity yang terlibat pada sistem lama Tidak 


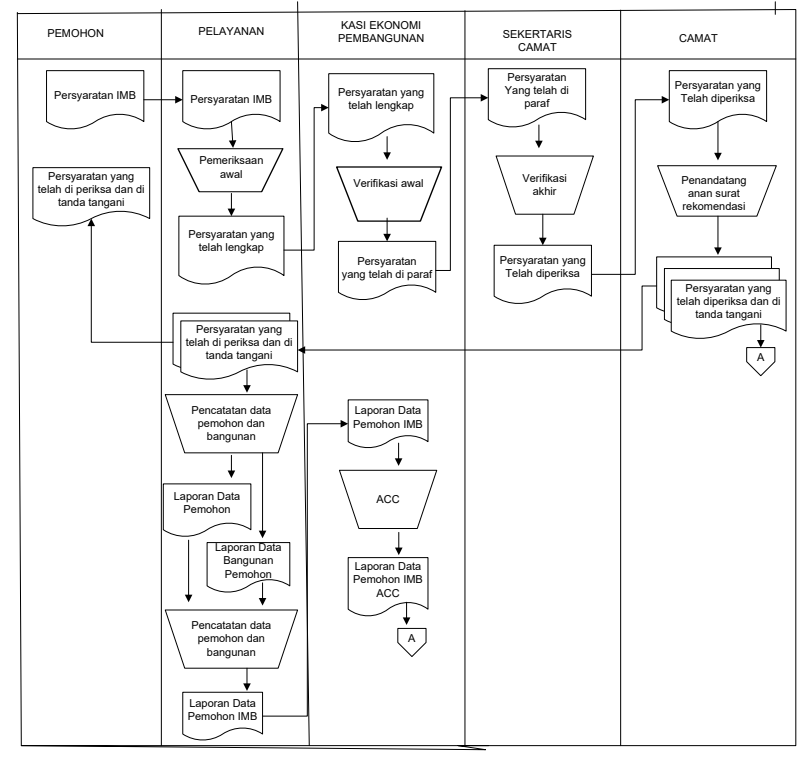

Gambar 2 Aliran sistem berjalan pada permohonan IMB

banyak berubah namun memiliki perbedaan dalam melakukan input data dan penyajian laporan. Dalam hal ini penulis mencoba membuat suatu sistem baru dari pengembangan yang ada, berupa sisstem baru, seperti terlihat pada Gambar 3.

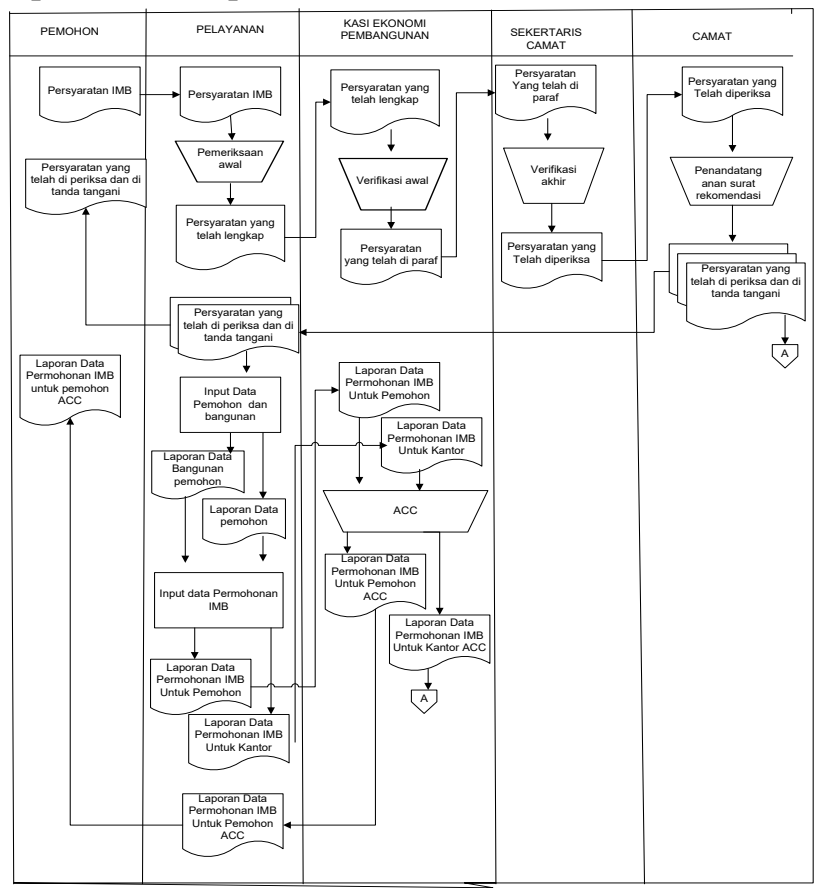

Gambar 3 Aliran sistem usulan

Pada aliran sistem informasi yang dirancang oleh penulis, terapat perbedaan pada bagian pelayanan dimana bagian ini telah melakukan peninputan data secara terkomputerisasi dan menambahkan sebuah laporan baru yaitu laporan permohonan imb yang diberikan kepada pemohon.

\section{Context Diagram}

Context Diagram adalah gambaran umum tentang suatu sistem yang terdapat didalam suatu organisasi yang memperlihatkan batasan (boundary) sistem, adanya interaksi antara eksternal entity dengan suatu sistem, dan informasi secara umum mengalir diantara entity dan sistem. Context Diagram ini merupakan alat bantu yang digunakan dalam menganalisa sistem yang akan dikembangkan. Context diagram pada pengolahan data IMB dapat dilihat pada Gambar 4.

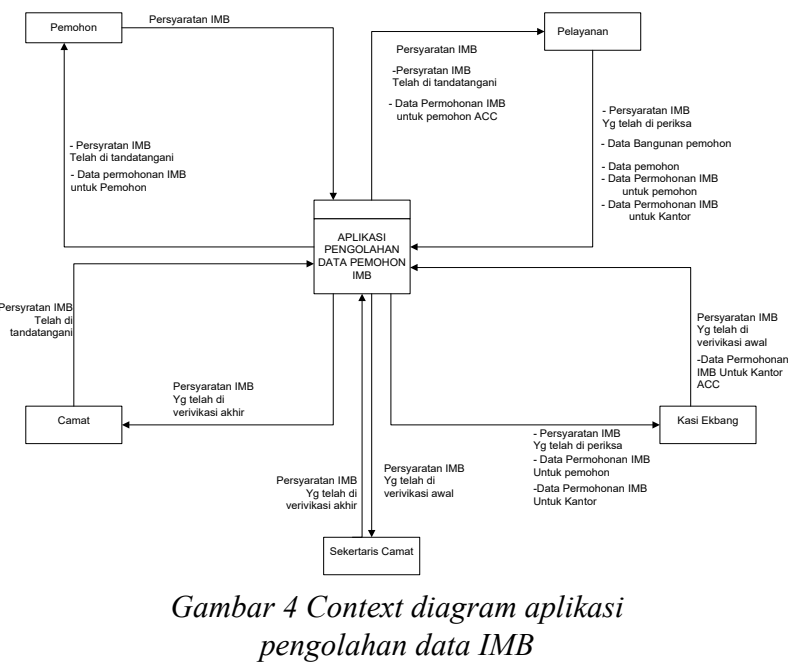

\section{E. Data Flow Diagram}

Untuk dapat menjelaskan secara lebih terinci mengenai sistem yang dirancang adalah menjabarkan Data Flow Diagram (DFD) dari sistem tersebut. Keuntungan dari penggunaan Data Flow Diagram adalah memudahkan pemakai atau User yang kurang menguasai bidang komputer untuk memahami sistem yang akan dikerjakan atau dikembangkan. Pengembangan Data Flow Diagram ini dimulai dari pembuatan Context Diagram dan dilanjutkan Data Flow Diagram Level 0. Data flow diagram pada sistem yang akan dirancang oleh penulis mengenai ppengolahan data permohonan IMB dapat dilihat pada Gambar 5.

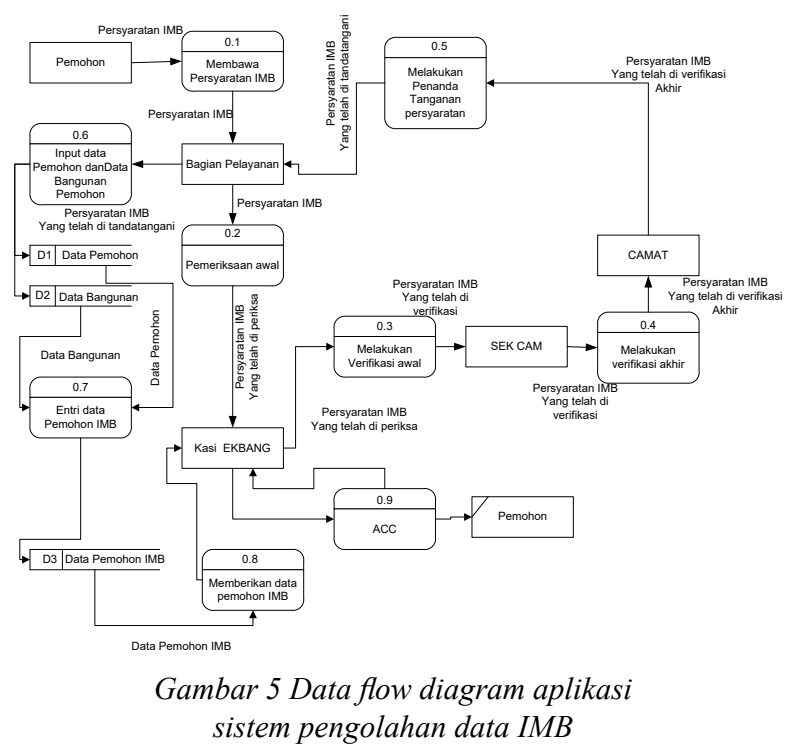




\section{F. Entity Relationship Diagram}

Entity Relationship Diagram (ERD) merupakan hubungan penerjemahan yang berisi komponenkomponen himpunan entiti dan himpunan relasi yang dilengkapi dengan atribut-atribut menghubungkan entiti tesebut digunakan key field (Primary Key Atribut) dari masing-masing entiti.

Pada gambar ini dijelaskan bahwa database yang dirancang terdiri dari tiga entiti yaitu entiti pemohon, entity bangunan, dan entity permohonan IMB. Setiap entity mempunyai atributnya masingmasing, salah satunya berfungsi sebagai primary key atau sebagai foreign key. Hubungan antar tabel yang ada pada sistem pengolahan data IMB dapat dilihat pada Gambar 6.

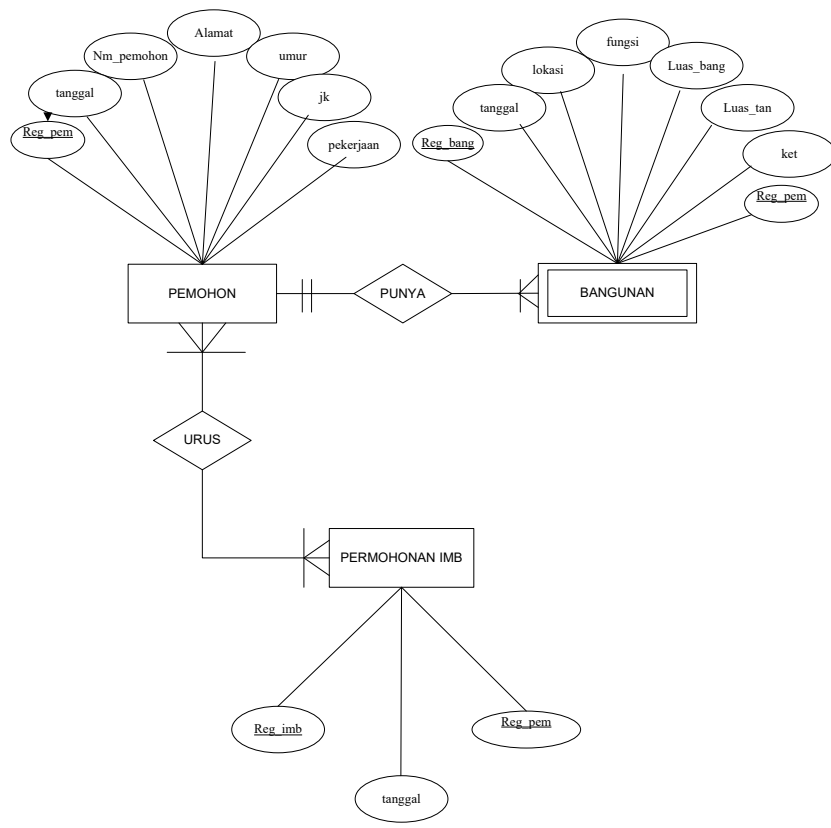

Gambar 6 Entity relationship diagram aplikasi pengolahan data IMB

\section{G. Struktur Program}

Struktur program merupakan gambaran dari masing-masing proses yang ada di dalam aplikasi pengolahan data IMB yang akan diimplementasikan sesuai dengan perancangan yang telah ditetapkan. Struktur program aplikasi pengolahan data IMB dapat dilihat pada Gambar 7.

Tampilan program dari system yang telah dirancang terdiri dari beberapa bagian yaitu login, menu input data dan laporan .

\section{a. Tampilan Login}

Tampilan login merupakann tampilan yang pertama yang akan ditemui oleh user dalam form ini terdapat dua bagian yaitu bagian admin dan bagian staff biasa. Tampilan login terlihat pada Gambar 8 .
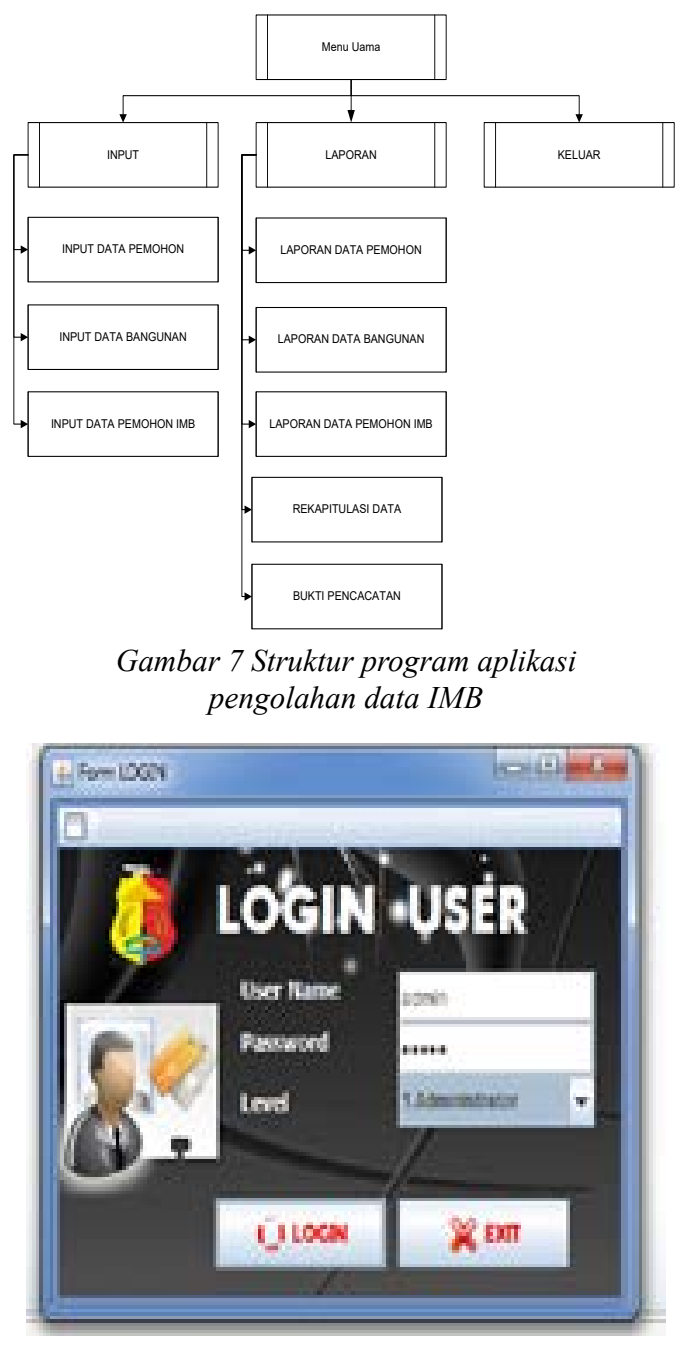

Gambar 8 Login program

\section{b. Tampilan menu utama}

Setelah login maka user akan memasuki halaman menu utama, menu utama terdiri dari menu input dan menu laporan. Tampilan menu utama dapat dilihat pada Gambar 9.

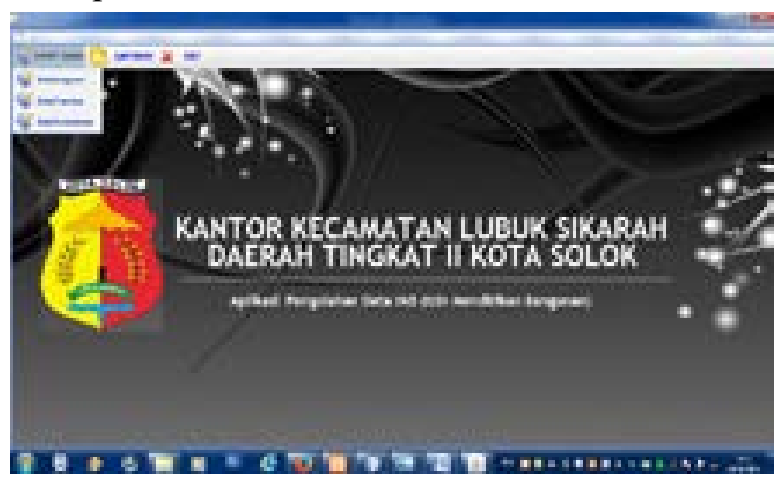

Gambar 9 Tampilan menu utama aplikasi $I M B$

\section{c. Tampilan input data}

Input data yang di rancang ada tiga macam yaitu input data pemohon dan input data bangunan dari kedua menu input ini akan menciptakan form input baru yaitu input data ermohonan IMB. Ketiga menu 
input tersebut dapat dilihat pada Gambar 10 dan 11. Input data pemohon berisi data pemohon yang melakukan permohonan pembuatan IMB.

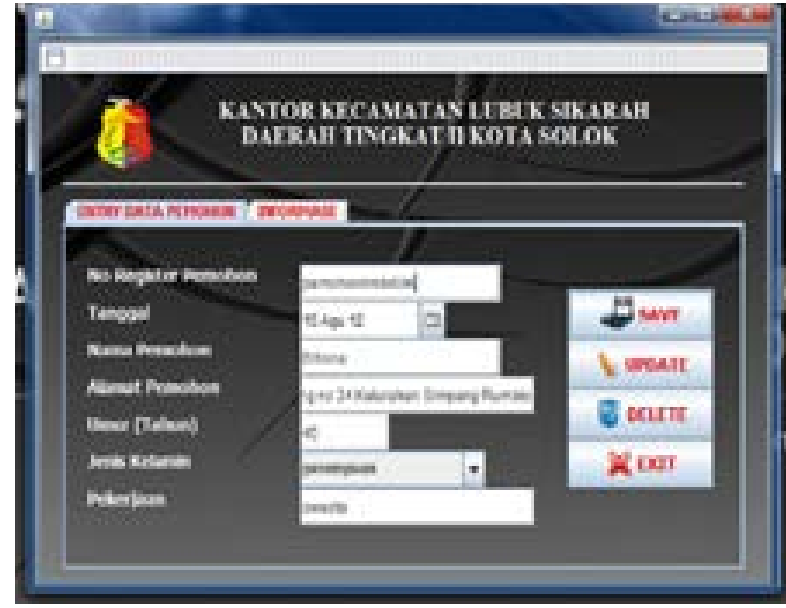

Gambar 10 Input data pemohon

Input data bangunan merupakan form yang berisikan data bangunan pemohon. Dapat dilihat pada Gambar 11.

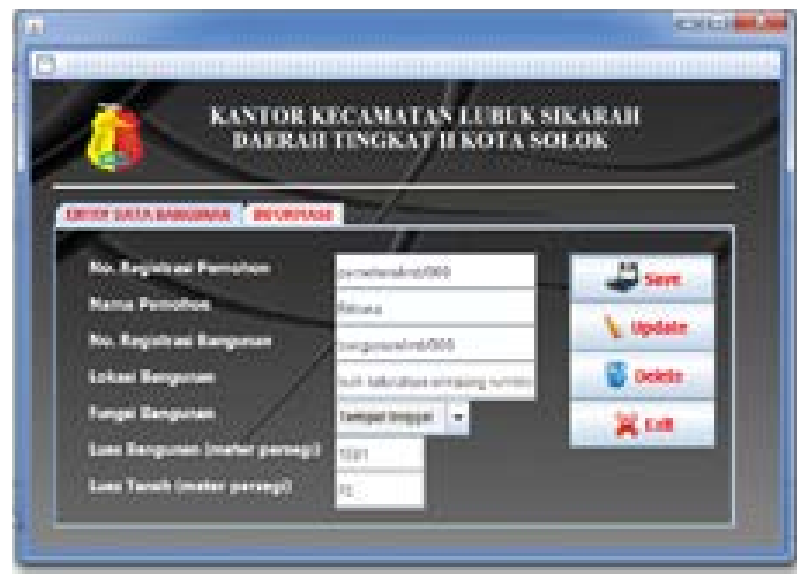

Gambar 11 Input data bangunan

Selain itu ada input data permohonan IMB merupakan input data yang berasal dari gabungan data pemohon dan bangunan yang saling berkaitan satu sama lain. Dapat dilihat pada Gambar 12.

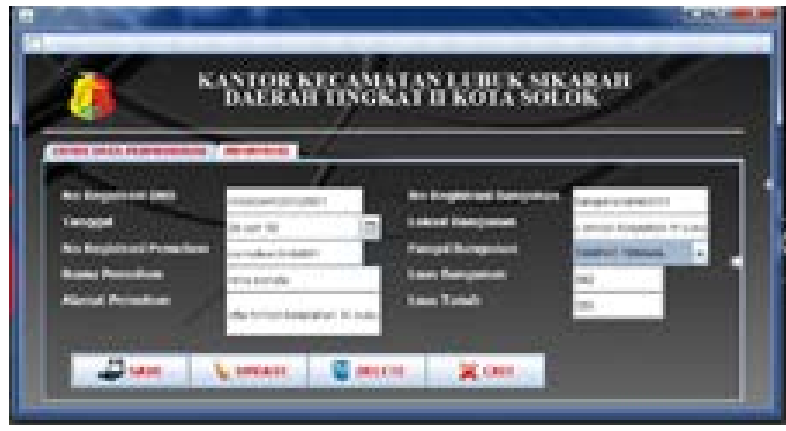

Gambar 12 Input data permohonan IMB

\section{d. Tampilan Laporan}

Setelah melakukan penginputan data dan diproses, hasil daricpemrosesan data menghasilkan informasi berupa laporan data . laporan data yang ada pada system ini terdiri dari beberapa laporan antara lain:

\section{Laporan data pemohon.}

Laporan data pemohon merupakan laporan data yang memuat semua masyarakat yang megajukan permohonan IMB. Dapat dilihat pada Gambar 13.

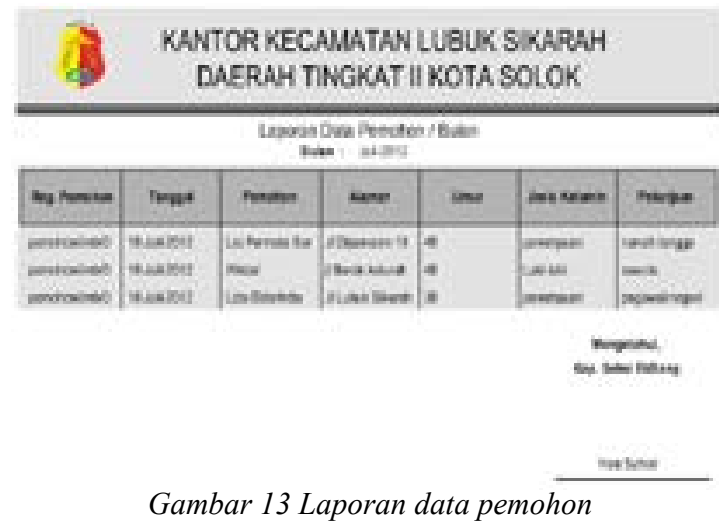

\section{Laporan data bangunan pemohon}

Merupakan laporan bangunan yang diurus IMB nya. Dapat dilihat pada Gambar 14.

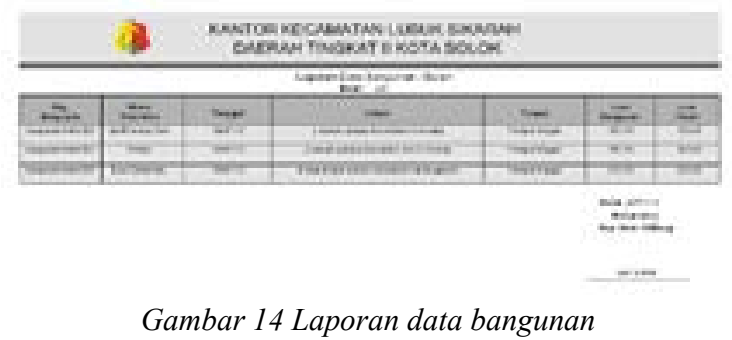

\section{Laporan data Permohonan IMB}

Merupakan kumpulan data keseluruhan yang berasal dari data pemohonan dan IMB. Dapat dilihat pada Gambar 15.

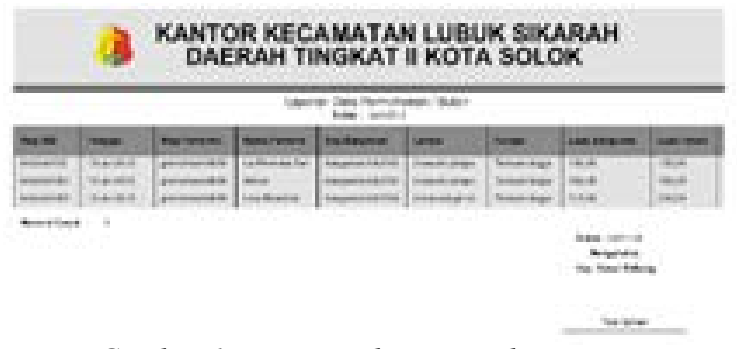

Gambar 15 Laporan data permohonan IMB

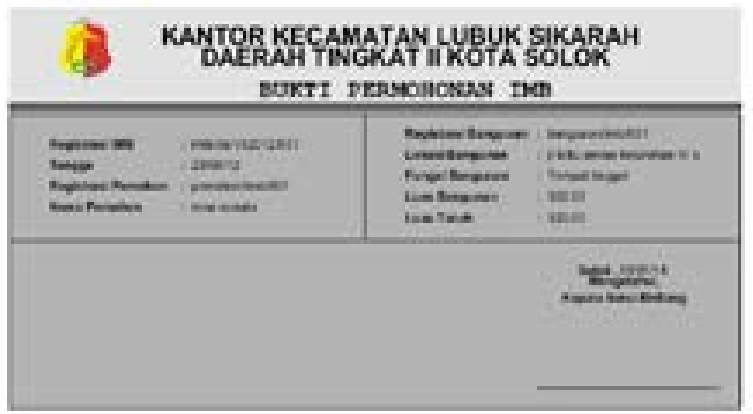

Gambar 16 Bukti permohonan IMB 


\section{Surat bukti permohonan IMB}

Merupakan laporan atau surat yang diterima oleh pemohon sebagai bukti telah melakukan pengurusan IMB. Dapat dilihat pada Gambar 16.

\section{SIMPULAN}

Dengan adanya sistem ini, dapat diambil suatu kesimpulan sebagai berikut : a) Dengan telah dirancangnya sebuah aplikasi pengolahan data permohonan izin mendirikan bangunan ini, membuat kinerja pegawai kecamatan dalam mengolah data menjadi lebih mudah dan cepat; b) Aplikasi Pengolahan data Permohonan izin mendirikan bangunan yang dilengkapi dengan database membuat penyimpanan data-data imb dapat lebih tertata dengan rapi dan lebih aman; dan c) Aplikasi pengolahan data permohonan izin mendrikan bangunan ini membuat pegawai lebih mudah dalam mencari informasi yang di inginkan.

\section{DAFTAR RUJUKAN}

[1] Pemerintah Kota Solok, Peraturan Daerah Kota Solok Tentang Bangunan Gedung. Indonesia, 2009
[2] K. I. P. Sari, "Mendirikan Bangunan Tanpa IMB Akan Merugikan Pemilik Bangunan," 2019. [Online]. Available: https://infopublik.solokkota.go.id/ himbauan-kepada-masyarakat-tentang-pengurusan$\mathrm{imb} /$

[2] B. J. Kaleb, "Penerapan Sistem Informasi Manajemen Dan Pengawasannya Di Kantor Pelayanan Pajak Pratama Manado,” J. EMBA J. Ris. Ekon. Manajemen, Bisnis dan Akunt., vol. 7, no. 1, pp. 781-790, 2019.

[2] Y. Heriyanto, "Perancangan Sistem Informasi Rental Mobil Berbasis Web Pada PT.APM Rent Car," J. IntraTech, vol. 2, no. 2, pp. 64-77, 2018.

[3] T. T. Loveri, "Sistem Informasi Aplikasi Pengelolaan Transaksi Keuangan Dan Pendataan Konsumen Pada Cv. Puplas,” J. Sains dan Inform., vol. 4, no. 2, p. 139 , 2018.

[4] I. Journal and S. Engineering, "603-1288-4-Pb,” Indones. J. Softw. Eng. Audit, vol. 2, no. 1, pp. 31-38, 2016.

[5] E. Tita, "Analisis Dan Perancangan Sistem Informasi Perpustakaan,” J. Sist. Inf., vol. 8, no. 1, pp. 966-977, 2016. 